\title{
KEPUASAN DAN LOYALITAS PELANGGAN AMING COFFEE: EXPERIENTIAL MARKETING
}

\author{
BELLA BELLINDA \\ EVA DOLOROSA \\ DEWI KURNIATI \\ Manajemen Agribisnis; Universitas Tanjungpura, Jl. Profesor Dokter H. Hadari Nawawi, Bansir Laut, Kec. \\ Pontianak Tenggara, Kota Pontianak, Kalimantan Barat, Indonesia \\ bella.bellinda31@gmail.com
}

\begin{abstract}
Aming Coffee is a coffee shop that is very well known by coffee connoisseurs in Pontianak. Over time, Aming coffee tried to get closer to the connoisseurs of Aming coffee by presenting a more modern appearance of the booth to provide comfort for the connoisseurs by increasing customer satisfaction and loyalty. However, with the number of coffee shops popping up in recent years, it is very influential for Aming coffee with the emergence of similar business competition, so this is a threat for Aming to continue to maintain satisfaction for its consumers. This study aims to analyze the effect of experiential marketing on Aming Coffee customer satisfaction and loyalty and the influence of satisfaction on Aming Coffee customer loyalty in Pontianak. This study used a questionnaire method with 150 respondents taken by purposive sampling at two Aming Coffee locations. Data analysis using SEM-PLS, WarpPLS 6.0 software. The results of this study indicate that experiential marketing variables significantly influence customer satisfaction and customer loyalty. The customer satisfaction variable mediates the effect of experiential marketing on customer loyalty. Customer satisfaction is the most influential factor in experiential marketing which can ultimately lead to customer loyalty. There needs to be an increase in all aspects of experiential marketing (sense, feel, think, act, relate) to support Aming Coffee to be a comfortable gathering place for visitors, especially young people and able to give prestige to visitors.
\end{abstract}

Keywords: Experiential marketing, sense, feel, think, act, relate, customer satisfaction, customer loyalty

Abstrak: Aming Coffee merupakan salah satu warung kopi yang sangat dikenal oleh penikmat kopi di Kota Pontianak. Seiring berjalannya waktu, Aming coffee berusaha mendekatkan kepada penikmat kopi Aming dengan menghadirkan tampilan gerai yang lebih modern untuk memberikan kenyamanan untuk para penikmatnya dengan meningkatkan kepuasan dan loyalitas pelanggan. Namun, dengan banyaknya bermunculan warung kopi beberapa tahun belakangan ini, sangat memberikan pengaruh bagi Aming coffee dengan munculnya persaingan bisnis yang sejenis, sehingga hal ini menjadi sebuah ancaman bagi Aming untuk tetap mempertahankan kepuasan bagi konsumennya. Penelitian ini bertujuan menganalisis pengaruh experiential marketing terhadap kepuasan dan loyalitas pelanggan Aming Coffee serta pengaruh kepuasaan terhadap loyalitas pelanggan Aming Coffee di Kota Pontianak. Penelitian ini menggunakan metode kuesioner dengan 150 responden yang diambil secara purposive sampling di dua lokasi Aming Coffee. Analisis data menggunakan SEM-PLS, software WarpPLS 6.0. Hasil penelitian ini menunjukan bahwa variabel experiential marketing berpengaruh signifikan terhadap kepuasan pelanggan dan loyalitas pelanggan. Variabel kepuasan pelanggan memediasi pengaruh experiential marketing terhadap loyalitas pelanggan. Kepuasan pelanggan merupakan faktor yang paling berpengaruh dalam experiential marketing yang akhirnya dapat menimbulkan loyalitas pada pelanggan. Perlu adanya peningkatan disemua aspek experiential marketing (sense, feel, think, act, relate) untuk menunjang Aming Coffee agar menjadi tempat yang 
berkumpul yang nyaman untuk pengunjung terutama kaum muda dan mampu memberikan prestise pada pengunjung.

Kata kunci: Experiential marketing, sense, feel, think, act, relate, kepuasan pelanggan, loyalitas pelanggan

\section{PENDAHULUAN}

Aming Coffee merupakan salah satu warung kopi tradisional yang sangat dikenal oleh penikmat kopi di Kota Pontianak sejak tahun 1970. Seiring berjalannya waktu, Aming coffee berusaha mendekatkan kepada penikmat kopi Aming dengan menghadirkan tampilan gerai yang lebih modern untuk memberikan kenyamanan untuk para penikmatnya dengan meningkatkan kepuasan dan loyalitas pelanggan. Aming coffee memberikan kenyamanan untuk para penikmat kopi Aming. Namun, dengan banyaknya bermunculan warung kopi beberapa tahun belakangan ini, sangat memberikan pengaruh bagi Aming coffee dengan munculnya persaingan bisnis yang sejenis, sehingga hal ini menjadi sebuah ancaman bagi Aming untuk tetap mempertahankan kepuasan bagi konsumennya.

Kepuasan pelanggan menjadi hal yang utama bagi Aming, sehingga Aming coffee terus berupaya dalam memberikan fasilitas yang dapat memanjakan pelanggannya. Kepuasan pelanggan merupakan tingkat perasaan senang atau kecewa seseorang sesudah membandingkan kinerja (hasil) dari suatu produk atau jasa yang telah dirasakan dan dibandingkan dengan harapannya (Kotler, 2009). Kepuasan pelanggan dapat terjadi disebabkan adanya pemenuhan harapan pelanggan atas suatu produk atau merek yang mereka konsumsi dan konsumen dengan tingkat kepuasan yang tinggi akan membentuk loyalitas secara konsisten dalam jangka waktu panjang (Levy \& Weitz, 2004). Pelanggan yang merasa puas yaitu pelanggan yang selalu berbagi kepuasan dengan pemasar dan dengan pelanggan lain, dan akan menimbulkan dampak pada loyal bagi perusahaan tersebut. Munculnya loyalitas pelanggan karena adanya pengaruh dari kepuasan yang telah dirasakan oleh pelanggan (Wijayanti 2008).

Upaya untuk mempertahankan dan meningkatkan kepuasan pelanggan perlu dilakukan berbagai strategi pemasaran yang tepat agar dapat mempertahankan dan meningkatkan loyalitas pelanggan. Salah satunya melalui strategi pemasaran dengan memberikan pengalaman unik yang bersifat positif dan tidak terlupakan kepada konsumen yang di kenal dengan istilah experiential marketing. Beberapa pengalaman unik dari Aming Coffee yaitu penyajian kopi Aming yang disuguhkan dengan penambahan taburan biji kopi dalam setiap gelasnya, sehingga membuat penikmat kopi merasakan adanya sensasi lain saat dapat mengulum atau mengunyah biji kopi tersebut secara langsung. Suasana ruangan yang bersih dan nyaman, serta fasilitas di Aming Coffee sangat berkesan. Keberagaman menu di Aming Coffee dapat memberikan banyak pilihan bagi konsumennya. Pelayanan karyawan Aming Coffee yang ramah dan memiliki kemampuan berkomunikasi yang baik dengan konsumennya.

Konsep experiential marketing ini ternyata selain memberikan fitur dan benefit dari suatu produk semata, tetapi juga dapat memberikan experience yang dapat memenuhi kebutuhan emosional pelanggan (Schmitt, 1999). Penelitian ini mengangkat isu experiential marketing dengan studi kasus pada coffee shop. Pelanggan coffee shop pada penelitian ini termasuk ke dalam objek penelitian, karena coffee shop merupakan produsen yang tidak hanya menawarkan minuman tetapi juga makanan, selain itu terdapat nilai tambah berupa pelayanan dan suasana yang muncul dari penataan interior/eksterior, fasilitas yang ada, ruangan yang bersih dan ramahnya karyawan kepada pelanggan, sehingga pelanggan tidak hanya merasa dipuaskan oleh produk yang telah mereka konsumsi, tetapi juga muncul dari 
pengalaman yang mereka dapatkan dari awal mula mereka datang ke coffee shop hingga mereka pulang (Nehemia, 2010).

Experiential marketing memiliki alat ukur atau pendekatan melalui Strategic Experiential Modules (SEMs) yaitu sense, feel, think, act, relate. Sense marketing adalah tipe experiential yang bermunculan untuk menciptakan pengalaman panca indera melalui lidah, hidung, telinga, mata, dan kulit. Feel marketing merupakan suatu perasaan dan emosi pelanggan yang bertujuan untuk mempengaruhi pengalaman yang dapat dimulai dari suasana hati yang lembut sampai dengan emosi yang kuat terhadap kesenangan atau kekecewaan. Think marketing ditujukan pada intelektual dengan maksud untuk menciptakan kesadaran (cognitive), pengalaman untuk mengatasi masalah yang mengajak pelanggan untuk berfikir kreatif. Act marketing bertujuan untuk mendesain dan menciptakan pengalaman pelanggan yang ada hubungannya dengan lifestyle, physical body, dan interaksi dengan orang lain. Relate marketing yaitu terdapat aspek-aspek dari sense, feel, think, act marketing serta mengutamakan pada penciptaan tanggapan dan tindakan yang positif dimata pelanggan (Schmitt, 1999).

Kepuasaan pelanggan adalah perasaan bahagia atau kecewa seseorang yang muncul sesudah membandingkan kinerja (hasil) produk yang diperhitungkan terhadap kinerja (hasil) yang diharapkan (Kotler \& Keller, Manajemen Pemasaran, 2009). Tiga aspek penting dalam kepuasan pelanggan, yaitu kesesuaian harapan, minat berkunjung kembali, kesediaan merekomendasikan (Hawkins \& Lonney, 2003). Pelanggan akan merasa puas terhadap suatu produk atau merek, maka mereka akan terus membeli dan menggunakan serta memberi tahu kepada orang lain tentang pengalaman (experience) mereka yang menyenangkan atau mengecewakan dengan produk tersebut (Paul \& Jerry C, 2000). Dari pendapat tersebut, dapat dikatakan bahwa pengalaman yaitu faktor penentu dari kepuasan pelanggan. Kunci utama penentu dari kepuasan pelanggan dan loyalitas merek merupakan pengalaman pelanggan selama mereka mengkonsumsi suatu produk. (Schmitt 1999).

Loyalitas pelanggan adalah komitmen pelanggan terhadap suatu merek dengan sikap yang menyenangkan dan positif, serta dapat menimbulkan pembelian ulang yang konsisten. Pelanggan yang loyal terhadap suatu merek memiliki karakteristik berupa berani membayar lebih pada produk tersebut bila bandingkan dengan merek yang lain, memiliki komitmen pada suatu produk tertentu, dalam melakukan pembelian kembali produk tersebut tidak melakukan pertimbangan, selalu mengikuti informasi yang berkaitan dengan produk tersebut, akan merekomendasikan produk tersebut pada orang lain, pelanggan dapat menjadi juru bicara dari produk tersebut dan mereka selalu membentangkan hubungan dengan produk tersebut (Giddens 2002). Penelitian ini bertujuan untuk menganalisis pengaruh experiential marketing terhadap kepuasan pelanggan dan loyalitas pelanggan, serta menganalisis pengaruh kepuasan pelanggan terhadap loyalitas pelanggan Aming Coffee di Kota Pontianak. Manfaat dari penelitian ini diharapkan dapat menjadi kajian pengembangan ilmu pengetahuan khususnya manajemen pemasaran yang berkaitan dengan strategi dari experiential marketing. Penelitian ini diharapkan dapat berguna untuk menambah pengalaman dan sebagai sarana untuk mengimplementasikan ilmu pengetahuan yang telah didapat dikursi kuliah dengan kenyataan yang terjadi sebenarnya. Penelitian ini juga diharapkan dapat menambah referensi dimasa mendatang bagi peneliti lainnya/selanjutnya, juga diharapkan dapat memberi saran atau masukan bagi Aming Coffee dan pihak lain seperti masyarakat mengenai pentingnya strategi experiential marketing sehingga dapat menciptakan kepuasan pelanggan yang akan memicu minat loyalitas pelanggan. 


\section{METODA}

Metode penelitian yang digunakan adalah penelitian kuantitatif (Sugiyono, 2014). Waktu penelitian dilakukan selama selama kurang lebih 3 bulan dan lokasi penelitian dilakukan secara purposive sampling, yaitu di Aming Coffee Transmart dan Bandara Supadio. Pengambilan sampel yang digunakan dalam penelitian ini adalah metode non-probability sampling dengan teknik purposive sampling dengan mengambil kurang lebih sebanyak 150 responden. Adapun sampel dalam penelitian ini adalah konsumen Aming
Coffee di Kota Pontianak dengan kriteria yang telah ditetapkan yaitu: responden yang berkunjung dan mengonsumsi kopi di Aming Coffee, usia responden diatas 17 tahun dan berperan sebagai pengambil keputusan, konsumen yang selalu menikmati hidangan Aming Coffee minimal sebanyak 2x dalam kurun waktu 1 bulan. Teknik pengumpulan data yang digunakan dalam penelitian ini adalah teknik angket/kuesioner, wawancara, studi pustaka. Analisis data menggunakan SEM-PLS software Warppls. Penelitian ini menggunakan SEM-PLS.

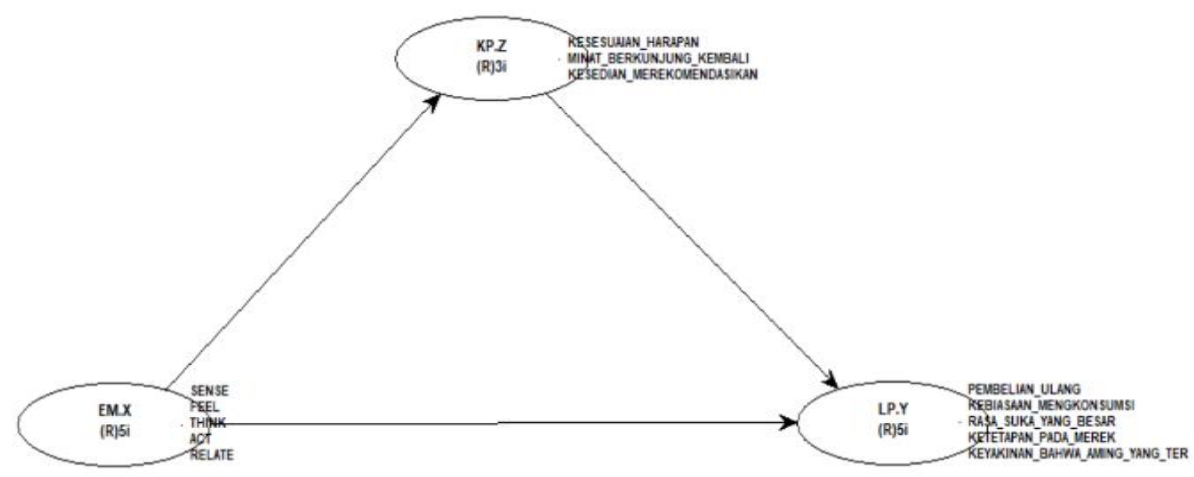

Gambar 1. Model SEM-PLS

Variabel yang diukur adalah experiential marketing $(X)$ sebagai variabel bebas dengan indikator berupa sense, feel, think, act, relate. Kepuasan pelanggan (Z) sebagai variabel intervening dengan indikator berupa kesesuaian harapan, minat berkunjung kembali, kesediaan merekomendasikan. Loyalitas pelanggan ( $\mathrm{Y}$ ) sebagai variabel terikat dengan indikator berupa pembelian ulang, kebiasaan mengonsumsi produk Aming Coffee, rasa suka yang besar pada produk Aming Coffee, ketetapan pada merek Aming Coffee, keyakinan bahwa Aming Coffee yang terbaik.

\section{HASIL DAN PEMBAHASAN}

Berikut demografi responden:

Tabel 1 Karakteristik Responden Berdasarkan Demografi

\begin{tabular}{lcc}
\hline Karakteristik Responden Berdasarkan Demografi & $\begin{array}{c}\text { Frekuensi } \\
\text { (Orang) }\end{array}$ & $\begin{array}{c}\text { Persentase } \\
\text { (\%) }\end{array}$ \\
\hline Usia & 6 & 4 \\
$<17$ Tahun & 128 & 85.3 \\
17 s/d $<25$ Tahun & 15 & 10 \\
25 s/d $<30$ Tahun & 1 & 0.7 \\
30 s/d 35 Tahun & & \\
\hline
\end{tabular}




\begin{tabular}{|c|c|c|}
\hline $\begin{array}{l}\text { Jenis Kelamin } \\
\text { Laki - laki } \\
\text { Perempuan }\end{array}$ & $\begin{array}{l}79 \\
71\end{array}$ & $\begin{array}{l}52.7 \\
47.3\end{array}$ \\
\hline \multicolumn{3}{|l|}{ Pendidikan Terakhir } \\
\hline $\begin{array}{l}\text { SD/Sederajat } \\
\text { SMP/Sederajat } \\
\text { SMA/Sederajat } \\
\text { Diploma } \\
\text { S1 } \\
\text { S2 } \\
\text { S3 }\end{array}$ & $\begin{array}{c}0 \\
0 \\
82 \\
14 \\
49 \\
3 \\
2\end{array}$ & $\begin{array}{c}0 \\
0 \\
54.7 \\
9.3 \\
32.7 \\
2 \\
1.3\end{array}$ \\
\hline $\begin{array}{l}\text { Pekerjaan Responden } \\
\text { PNS } \\
\text { Pegawai Swasta }\end{array}$ & $\begin{array}{c}2 \\
31 \\
\end{array}$ & $\begin{array}{c}1.3 \\
20.6 \\
\end{array}$ \\
\hline Karakteristik Responden Berdasarkan Demografi & $\begin{array}{l}\text { Frekuensi } \\
\text { (Orang) }\end{array}$ & $\begin{array}{c}\text { Persentase } \\
(\%)\end{array}$ \\
\hline $\begin{array}{l}\text { BUMN/BUMD } \\
\text { Wirausaha } \\
\text { TNI / POLRI } \\
\text { Pelajar / Mahasiswa } \\
\text { Lainnya (Honorer, Kontrak, dll) }\end{array}$ & $\begin{array}{c}7 \\
18 \\
4 \\
81 \\
7\end{array}$ & $\begin{array}{l}4.7 \\
12 \\
2.7 \\
54 \\
4.7\end{array}$ \\
\hline $\begin{array}{l}\text { Pendapatan Responden } \\
<\operatorname{Rp} 1.000 .000 \\
\operatorname{Rp} 1.000 .000 \mathrm{~s} / \mathrm{d}<\operatorname{Rp} 2.000 .000 \\
\operatorname{Rp} 2.000 .000 \mathrm{~s} / \mathrm{d}<\operatorname{Rp} 3.000 .000 \\
\operatorname{Rp} 3.000 .000 \mathrm{~s} / \mathrm{d}<\operatorname{Rp} 4.000 .000 \\
\operatorname{Rp} 4.000 .000 \mathrm{~s} / \mathrm{d}<\operatorname{Rp} 5.000 .000 \\
\operatorname{Rp} 5.000 .000\end{array}$ & $\begin{array}{l}22 \\
25 \\
27 \\
11 \\
8 \\
11\end{array}$ & $\begin{array}{l}14.7 \\
16.7 \\
18.0 \\
7.3 \\
5.3 \\
7.3\end{array}$ \\
\hline $\begin{array}{l}\text { Uang Saku Responden } \\
<\operatorname{Rp} 500.000 \\
500.000 \mathrm{~s} / \mathrm{d}<\operatorname{Rp} 1.000 .000 \\
\operatorname{Rp} 1.000 .000 \mathrm{~s} / \mathrm{d}<\operatorname{Rp} 1.500 .000 \\
\operatorname{Rp} 1.500 .000 \mathrm{~s} / \mathrm{d}<\operatorname{Rp} 2.000 .000 \\
\operatorname{Rp} 2.000 .000 \mathrm{~s} / \mathrm{d}<\operatorname{Rp} 2.500 .000 \\
\operatorname{Rp} 2.500 .000\end{array}$ & $\begin{array}{c}25 \\
0 \\
13 \\
5 \\
2 \\
1\end{array}$ & $\begin{array}{c}16.7 \\
0 \\
8.7 \\
3.3 \\
1.3 \\
0.7 \\
\end{array}$ \\
\hline
\end{tabular}

Sumber: Data olahan

Karakteristik responden pelanggan Aming Coffee digambarkan melalui aspek demografi diantaranya usia, jenis kelamin, pendidikan terakhir, pekerjaan, pendapatan uang saku. Berdasarkan usia responden pada penilitian ini didominasi oleh kelompok usia $>17-25$ tahun yang termasuk dalam kategori masa dewasa awal. Hal ini menunjukkan bahwa responden dalam penelitian ini merupakan kelompok usia remaja menuju dewasa, yang dimana pada kelompok usia ini seringkali melakukan kegiatan untuk berkumpul dan bersantai bersama teman-teman. Secara umum dilihat bahwa responden yang datang ke Aming Coffee Transmart Carrefour Kubu Raya dan Aming Coffee Bandara Supadio didominasi oleh responden berjenis kelamin laki-laki. Hal ini 
menunjukkan bahwa jumlah laki-laki lebih banyak daripada perempuan dikarenakan lokasi coffee shop terdapat smoking area yang dimana jumlah laki-laki yang merokok lebih banyak dibandingkan dengan perempuan. Selain itu, lokasi coffee shop yang berada di wilayah Mall dapat dijadikan salah satu tempat tujuan sebagian besar laki-laki dalam menunggu pasangan atau keluarganya saat sedang shopping atau meeting (Stenley, 2009).

Pada kategori tingkat pendidikan terakhir dapat dilihat bahwa responden paling banyak dalam penelitian ini berpendidikan terakhir SMA/Sederajat. Hal ini menunjukkan bahwa hampir setengah dari total responden memiliki jenjang pendidikan menengah tinggi dimana responden akan berpikir kritis dan selektif dalam menuntukan pilihan untuk melakukan pembelian atau berkunjung ke suatu tempat (Moerbeek \& Casimir, 2005). Karakteristik responden berdasarkan pekerjaan dapat dilihat bahwa responden paling banyak adalah Pelajar/Mahasiswa. Hal ini dikarenakan pelajar mempunyai beberapa alasan untuk mengunjungi coffee shop seperti hanya sekedar minum kopi, mengerjakan tugas, bertemu dengan teman, menghilangkan rasa bosan. Sehingga pada kelompok konsumen ini lebih memilih sebuah coffee shop yang memiliki fasilitas yang lengkap seperti AC dan wifi yang memberikan kenyamanan untuk mengerjakan beberapa aktivitas di dalam coffee shop tersebut (Utami, 2009).

Jumlah responden paling banyak terdapat pada tingkat pendapatan > Rp 2.000.000-Rp 3.000.000. Hal ini menunjukan bahwa lebih dari setengah responden sudah memiliki tingkat pendapatan menengah sehingga responden tidak terlalu peka terhadap harga, akan tetapi responden dengan pendapatan menengah lebih peka pada pelayanan yang didapatkan dari Aming Coffee Transmart Carrefour Kubu Raya dan Aming Coffee Bandara Supadio. Tingkat uang saku responden paling banyak terdapat pada tingkat uang saku $\leq R p 500.000$ sebesar 16.7 persen. Hal ini menunjukan bahwa pada umumnya Aming Coffee dapat dijangkau oleh kalangan menengah muda yang masih dibiayai oleh orang tua mereka (Febrinda 2017).

\section{Tabel 2 Karakteristik Responden Berdasarkan Konsumsi Kopi Aming}

\begin{tabular}{lcc}
\hline $\begin{array}{l}\text { Karakteristik Responden Berdasarkan Konsumsi } \\
\text { Kopi Aming }\end{array}$ & $\begin{array}{c}\text { Frekuensi } \\
\text { (Orang) }\end{array}$ & $\begin{array}{c}\text { Persentase } \\
\text { (\%) }\end{array}$ \\
\hline Jumlah Kunjungan & 107 & 71.3 \\
3 - 4 Kali & 13 & 8.7 \\
5 - 6 Kali & 30 & 20 \\
6 Kali < & & \\
Alasan Sering Datang Ke Gerai Tersebut & 63 & 20.1 \\
Lokasi strategis/mudah dijangkau & 72 & 22.9 \\
Harga lebih murah & 18 & 5.8 \\
Harga jelas / transparan & 14 & 4.5 \\
Kualitas lebih baik & 17 & 5.4 \\
Variasi menu lebih banyak / lebih beragam & 26 & 8.3 \\
Pelayanan yang baik dari karyawan / tenaga penjual & 13 & 4.1 \\
Terkesan berkelas & 68 & 21.6 \\
Suasana terasa nyaman & 14 & 4.4 \\
Tempat/ruangan luas & 9 & 2.9 \\
Alasan lainnya, silahkan disebutkan &
\end{tabular}

Sumber: Data olahan 
Hasil penelitian menunjukkan bahwa alasan responden berkunjung ke gerai cafe selain Aming Coffee Transmart Carrefour Kubu Raya dan Aming Coffee Bandara Supadio dapat dilihat bahwa responden paling banyak memberikan alasan harga paling murah sebesar 22.9 persen, suasana terasa nyaman sebesar 21.6 persen, dan lokasi strategis / mudah dijangkau sebesar 20.1 persen. Hal ini menunjukkan bahwa gerai cafe tersebut dapat membuat konsumen merasa nyaman dengan experiential marketing yang ada pada gerai cafe tersebut pada saat berkunjung dan lokasi pada gerai tersebut sangat mudah untuk dijangkau oleh pelanggan karena letaknya di pusat Kota Pontianak.

Suatu penelitian akan menghasilkan kesimpulan yang biasa jika datanya kurang reliabel dan kurang valid. Maka, diperlukan uji kualitas data agar data yang akan digunakan valid dan reliabel. Konsep untuk mengukur kualitas data terbagi menjadi dua, yaitu: uji validitas dan uji realibilitas. Hasil uji validitas konvergen menyatakan bahwa semua indikator dari tiap variabel memiliki nilai factor loading yang lebih besar dari 0.5 yang berarti semua indikator memenuhi kriteria validitas konvergen. Hasil uji reliabilitas komposit menunjukan nilai koefisien Composite Reability (C.R) seluruh variabel laten yang digunakan dalam penelitian $>0.7$ dan cronbach's alpha $>0.6$ yang berarti bahwa seluruh item pengukuran variabel laten dianggap handal dalam mengukur variabel yang ingin diukur.

Tabel 3 Indeks Ketepatan dan Kualitas Model

\begin{tabular}{|c|c|c|c|c|}
\hline No & Indeks & Nilai Rujukan & Nilai Ril & Keterangan \\
\hline 1 & Average path coefficient (APC) & $P<0,05$ & $P<0,001$ & Terpenuhi \\
\hline 2 & Average R-squared (ARS) & $P<0,05$ & $P<0,001$ & Terpenuhi \\
\hline 3 & $\begin{array}{l}\text { Average adjusted R-squared } \\
\text { (AARS) }\end{array}$ & $P<0,05$ & $P<0,001$ & Terpenuhi \\
\hline 4 & Average block VIF (AVIF) & $\begin{array}{c}\leq 3,3 \\
\text { acceptable if } \leq 5\end{array}$ & 2,291 & Terpenuhi \\
\hline 5 & $\begin{array}{l}\text { Average full collinearity VIF } \\
\text { (AFVIF) }\end{array}$ & $\begin{array}{c}\leq 3,3 \\
\text { acceptable if } \leq 5 \\
\text { small } \geq 0,1\end{array}$ & 2,370 & Diterima \\
\hline 6 & Tenenhaus GoF (GoF) & $\begin{array}{l}\text { medium } \geq 0,25 \\
\text { large } \geq 0.36\end{array}$ & 0,604 & Large \\
\hline 7 & Sympson's paradox ratio (SPR) & $\begin{array}{c}\text { acceptable if }>=0,7 \\
\text { ideally }=1\end{array}$ & 1,000 & Terpenuhi \\
\hline 8 & $\begin{array}{l}\text { R-squared contribution ratio } \\
\text { (RSCR) }\end{array}$ & $\begin{array}{c}\text { acceptable if }>=0,9 \\
\text { ideally }=1\end{array}$ & 1,000 & Terpenuhi \\
\hline 9 & $\begin{array}{l}\text { Statistical suppression ratio } \\
\text { (SSR) }\end{array}$ & $\geq 0,7$ & 1,000 & Terpenuhi \\
\hline 10 & $\begin{array}{l}\text { Nonlinear bivariate causality } \\
\text { direction ratio (NLBCDR) }\end{array}$ & $\geq 0,7$ & 1,000 & Terpenuhi \\
\hline
\end{tabular}

Berdasarkan tabel 3 hasil pengujian indeks ketepatan dan kualitas model dapat dilihat bahwa nilai $P$-value APC sebesar $P<0.001$ dan
ARS sebesar $P<0.001$ yang berarti $<0.05$. Dapat disimpulkan bahwa model yang dihipotesiskan sudah sesuai dengan data observasi. 
Tabel 4 Indeks Ketepatan dan Kualitas Model

\begin{tabular}{cccccc}
\hline Hipotesis & \multicolumn{2}{c}{$\begin{array}{c}\text { Hubungan antara Variabel } \\
\text { (Variabel Penjelas } \rightarrow \text { Variabel Respon) }\end{array}$} & $\begin{array}{c}\text { Koef. } \\
\text { Jalur }\end{array}$ & P-value & Keterangan \\
\hline H1 & $\begin{array}{c}\text { Experiential } \\
\text { Marketing }(\mathrm{X})\end{array}$ & Kepuasaan Pelanggan (Z) & 0,763 & $<0,001$ & Signifikan \\
H2 & $\begin{array}{c}\text { Experiential } \\
\text { Marketing }(\mathrm{X})\end{array}$ & Loyalitas Pelanggan $(\mathrm{Y})$ & 0,226 & $\mathbf{0 , 0 0 2}$ & Signifikan \\
Kepuasaan & Loyalitas Pelanggan (Y) & 0,500 & $<0,001$ & Signifikan \\
\hline
\end{tabular}

Sumber: Output statistik

Hasil uji hipotesis menunjukan bahwa experiential marketing berpengaruh signifikan terhadap kepuasan dan loyalitas pelanggan Aming Coffee diterima. Kepuasan pelanggan berpengaruh positif terhadap loyalitas pelanggan, artinya adanya pengaruh yang kuat antara kepuasan pelanggan terhadap loyalitas pelanggan. Pengunjung Aming Coffee yang menjadi responden dalam penelitian ini menunjukan bahwa adanya pengaruh yang positif terhadap aspek sense (panca indera), feel (perasaan), think (berpikir), act (tindakan), relate (hubungan). Dalam penelitian ini, aspek sense (panca indera) yang diberikan oleh Aming Coffee dapat menyentuh sisi pengalaman konsumen meliputi tampilan desain interior dan eksterior Aming Coffee yang tampak menarik di mata konsumen, penampilan karyawan yang menggunakan seragam terlihat rapi bagi konsumen, adanya suara musik yang dapat menambah kenyamanan konsumen saat menikmati kopi yang disajikan, ditambah dengan adanya aroma kopi yang khas di hidangan yang sajikan oleh Aming Coffee dapat membangkitkan selera minum bagi konsumen.

Aspek feel (perasaan) yang diberikan oleh Aming Coffee dapat menyentuh sisi pengalaman konsumen. Responden memberikan tanggapan bahwa suasana ruangan Aming Coffee yang nyaman dapat menambah kesenangan konsumen saat berkumpul bersama kerabat mereka, ramahnya karyawan yang ada di Aming Coffee juga dapat memberikan kepuasan bagi konsumen, dan kebersihan ruangan Aming Coffee yang terjaga dengan baik dapat membangkitkan selera dalam menikmati kopi yang disajikan. Responden memberikan tanggapan bahwa aspek think (berpikir) yang diberikan oleh Aming Coffee dapat menyentuh sisi pengalaman konsumen meliputi letak Aming Coffee yang menyebar di banyak kota membuat pelanggan berpikir bahwa Aming Coffee merupakan coffee shop lokal yang reputasinya sudah terkenal, lokasi Aming Coffee yang strategis membuat pelanggan berpikir mudah untuk dijangkau konsumen, dan banyaknya jumlah pengunjung Aming Coffee membuat pelanggan berpikir bahwa kopi yang disajikan rasanya nikmat sehingga dapat mempengaruhi kepuasan pelanggan Aming Coffee.

Aspek act (tindakan) menunjukan alasan utama konsumen mengunjungi Aming Coffee didominasi oleh kondisi ruangan dan fasilitas di Aming Coffee sangat berkesan sehingga membuat pelanggan merasa ingin kembali menikmati kopi yang disajikan. Selain itu, karyawan Aming Coffee juga mempunyai kemampuan berkomunikasi yang baik dengan konsumennya dan mampu mengkomunikasikan dengan baik informasi seputar produk terbarunya melalui sosial media. Responden memberikan tanggapan tentang aspek relate (hubungan) yang meliputi Aming Coffee menjadi pilihan tempat untuk mengisi waktu luang saat berkumpul bersama kerabat, layanan Aming Coffee yang professional juga memberikan kesimpulan bahwa Aming Coffee memiliki budaya kerja yang memberikan pelayanan prima kepada konsumennya, dan hang out (berkumpul) di Aming Coffee sudah menjadi trend oleh sekelompok kalangan muda di Kota Pontianak khususnya. 
Hasil analisis menunjukan bahwa Aming Coffee memiliki kinerja yang sesuai atau bahkan melebihi harapan pelanggan sehingga pelanggan dapat merasa senang dan puas ketika berada di Aming Coffee. Aming Coffee dapat dikatakan mampu memenuhi harapan responden dan membuat pengunjung menjadi loyal. Semakin baik penerapan experiential marketing di coffee shop, maka kepuasan pelanggan akan semakin meningkat. Sebaliknya semakin rendah experiential marketing di coffee shop, maka kepuasan pelanggan juga akan semakin berkurang (Wang \& Lin, 2010). Kepuasan pelanggan akan meningkat jika experiential marketing diperhatikan. Kelima aspek experiential marketing dapat memberikan nilai lebih pada Aming Coffee, sehingga mampu mempengaruhi pengunjung untuk menjadi loyal.

Semua yang dirasakan oleh responden mampu mendorong responden untuk membagikan informasi positif, menceritakan pengalaman saat berkunjung, merekomendasikan Aming Coffee kepada orang lain, dan mengajak teman atau kerabat ke Aming Coffee. Kepuasan konsumen yang dihasilkan dari experiential marketing pada akhirnya dapat menimbulkan loyalitas pada diri konsumen. Oleh karena itu, experiential marketing secara langsung dapat mempengaruhi keinginan pelanggan untuk mengkonsumsi suatu produk atau jasa (Ming, 2010). Semua hal yang dirasakan oleh responden mampu mendorong responden untuk membagikan informasi positif, menceritakan pengalaman saat berkunjung, merekomendasikan Aming Coffee kepada orang lain, dan mengajak teman atau kerabat ke Aming Coffee. Hasil penelitian (Dewi, Kumadji, \& Mawardi, 2015) juga menunjukan bahwa variabel experiential marketing berpengaruh signifikan terhadap kepuasan pelanggan. Penelitian oleh (Christian \& Dharmayanti, 2013) juga menunjukan bahwa variabel experiential marketing berpengaruh signifikan terhadap loyalitas pelanggan.
Hasil tanggapan responden terhadap variabel kepuasan pelanggan menunjukan bahwa konsumen tetap berkeinginan untuk menikmati kopi di Aming Coffee di waktu yang akan datang, Aming Coffee mampu memberikan pelayanan yang sesuai dengan harapan pelanggan, pelanggan merekomendasikan Aming Coffee sebagai tempat nongkrong yang nyaman dan membagikan informasi-informasi positif tentang Aming Coffee kepada orang terdekat. Hal ini menunjukan bahwa pengunjung sudah mendapatkan apa yang mereka harapkan dan menjadikan responden merasa puas sehingga menimbulkan loyalitas. Dapat dikatakan bahwa Aming Coffee sudah maksimal dalam memberikan kepuasan dan loyalitas kepada pengunjung.

Hubungan antara kepuasan pelanggan dan loyalitas pelanggan dapat digambarkan sebagai garis lurus yang searah, artinya apabila suatu badan usaha meningkatkan kepuasan kepada pelanggannya maka loyalitas pelanggan juga akan meningkat, begitu pula jika suatu badan usaha menurunkan kepuasan pelanggannya maka loyalitas pelanggan juga akan menurun (Lopumeten \& Tomasoa, 2018). Salah satu manfaat dari kepuasan pelanggan yaitu dapat menimbulkan pembelian ulang. Meningkatnya kepuasan pelanggan akan berdampak pada meningkatnya perasaan loyal bagi pelanggan dan memicu minat pelanggan untuk datang kembali ke tempat yang sama untuk melakukan pembelian ulang (Guiltinan 1997). Maka dapat disimpulkan bahwa semakin besar tingkat kepuasan pelanggan Aming Coffee maka semakin tinggi pula tingkat pembelian ulang oleh pelanggan Aming Coffee. Maka kepuasan pelanggan berpengaruh signifikan terhadap loyalitas pelanggan Aming Coffee Transmart Carrefour Kubu Raya dan Aming Coffee Bandara Supadio diterima. Penelitian yang dilakukan oleh (Panjaitan, 2017) menunjukkan terdapat hubungan positif yang signifikan antara kepuasan konsumen terhadap loyalitas pelanggan. 
Tabel 5 Pengaruh Tidak Langsung

\begin{tabular}{ccccc}
\hline No & Variabel Penjelas & $\begin{array}{c}\text { Variabel } \\
\text { Mediasi }\end{array}$ & $\begin{array}{c}\text { Variabel } \\
\text { Respon }\end{array}$ & P-value \\
\hline $1 \quad$ Experiential Marketing $(\mathrm{X})$ & $\mathrm{KPZ}$ & LPY & $<0,001$ \\
\hline Sumber: Output statistik & & &
\end{tabular}

Hasil perhitungan pengaruh tidak langsung dapat diinterpretasikan bahwa nilai signifikansi pengaruh tidak langsung experiential marketing $(\mathrm{X})$ terhadap loyalitas pelanggan ( $\mathrm{Y}$ ) melalui kepuasan pelanggan (Z) sebesar $<0.001$ yang berarti bahwa kepuasan pelanggan (Z) memediasi pengaruh experiential marketing terhadap loyalitas pelanggan.

\section{PENUTUP}

Hasil analisis data dan pembahasan yang telah dijelaskan yaitu experiential marketing berpengaruh signifikan terhadap kepuasan dan loyalitas pelanggan, serta kepuasan pelanggan berpengaruh signifikan terhadap loyalitas pelanggan. Maka, dapat dikatakan bahwa Aming Coffee memiliki kinerja yang sesuai dengan harapan pelanggan dari aspek sense yang ada di Aming Coffee dapat membuat pengunjung menjadi loyal, karena pengunjung sudah mendapatkan pengalaman panca indera seperti yang diharapkan, aspek feel yang dirasakan pelanggan sesuai dengan harapan sehingga pelanggan mendapatkan suasana yang mereka butuhkan ketika berkunjung, aspek think yang diberikan oleh Aming Coffee dapat menyentuh sisi pengalaman pelanggan melalui ingatan yang tersimpan dalam pikiran pelanggan terhadap Aming Coffee, aspek act yang ada di Aming Coffee dapat memberikan pengalaman kepada pelanggan dengan pengalaman tubuh atau aktivitas yang terjadi saat mengkonsumsi produk, gaya hidup, dan interaksi, aspek relate yang diberikan oleh Aming Coffee dapat menyentuh sisi pengalaman yang ditawarkan kepada pelanggan berkaitan dengan aspek sosial meliputi adanya komunitas anak muda di Aming Coffee. Semua hal yang diberikan oleh Aming Coffee mampu membuat pelanggan datang berkunjung kembali dan melakukan pembelian ulang yang berdampak pada meningkatnya loyalitas pelanggan. Hasil penelitian yang telah dipaparkan, terdapat keterbatasan pada penelitian ini, seperti cakupan wilayah penelitian ini hanya di dua cabang Aming Coffee sehingga kurang mampu mewakili di cabang lain, maka arah riset kedepan perlu dilakukan penelitian dengan cakupan yang lebih luas lagi.

\section{REFERENCES:}

Chrisitian , A., \& Dharmayanti, D. 2013. Pengaruh Experiential Marketing Terhadap Customer Satisfaction dan Customer Loyalty The Light Cup di Surabaya Town Square. Manajemen Pemasaran, 1(2), 1-13.

Dewi, R. K., Kumadji, S., \& Mawardi, M. K. 2015. Pengaruh Experiential Marketing terhadap Kepuasan Pelanggan dan dampaknya terhadap Loyalitas Pelanggan (Survei Pada Pelanggan Tempat Wisata Jawa Timut Park 1 Kota Wisata Batu). Administrasi Bisnis, 28(1), 1-6.

Febrinda, Y. 2017. Analisis Pengaruh Gaya Hidup, Kelompok Referensi, dan Lokasi Terhadap Keputusan Berkunjung Di Warung Kopi Aming Kota Pontianak. Pontianak: Universitas Tanjungpura.

Giddens. 2002. Customer Loyalty Menumbuhkan dan Mempertahankan Kesetiaan Pelanggan. (D. K. Jaya, Trans.) Jakarta: Erlangga.

Guiltinan, P., \& Madden. 1997. Marketing Management Strategies and Program. New Bakersfield: McGraw Hill. 
Hawkins, \& Lonney. 2003. Faktor - Faktor yang Mempengaruhi Kesetiaan Terhadap Merek Pada Konsumen Pasta Gigi Pepsodent di Surabaya. Ekonomi Terpadu, 37, 36-50.

Kotler, P. 2009. Manajemen Pemasaran. Jakarta: Erlangga.

Levy, M., \& Barton , A. W. 2004. Retailing Management (5 ed.). New York: McGraw - Hill.

Lopumeten, R. N., \& Tomasoa, S. K. 2018. Pengaruh Experiential Marketing dan Kepuasan Pelanggan Terhadap Loyalitas Pelanggan. Jurnal SOSO2, 34-50.

Ming, Y.-M. 2010. Study on Impact of Experiential Marketing and Customer. The International Journal of Organizational Innovation, 3(1), 189-209.

Mokhtar, S. S., \& Maiyaki, A. A. 2011. Impact Of Service Quality On Customer Satisfaction In Restaurant Industry. School of Doctoral Studies (European Union), 32-38.

Nehemia, H. S. 2010. Analisis Pengaruh Experiential Marketing terhadap Loyalitas pelanggan (Studi Kasus Waroeng Spesial Sambal cab.Sompok - Semarang). Manajemen Pemasaran, 5-10.

Panjaitan, D. F. 2017. Pengaruh Experiential Marketing Terhadap Loyalitas Konsumen Yang Dimediasi Variabel Kepuasan Konsumen (Studi Kasus: Fitness First Cabang Oakwood). Media Manajemen Jasa, 4(1), 4460.

Paul, P. J., \& Jerry C, O. 2000. Consumer Behavior: Perilaku Konsumen dan Strategi Pemasaran. Jakarta: Erlangga.

Schmitt, B. H. 1999. Experriential Marketing: How to Get Customer to Sense, Feel, Think, Act and Relate. New York: The Free Press.

Stenley, I. 2009. Analisis kepuadan dan loyalitas konsumen coffee shop warung kopi serta impilkasinya terhadap strategi pemasaran. Bogor : Departemen Agribisnis.

Sugiyono. 2014. Metode Penelitian Bisnis. Bandung: Alfabeta.

Utami, D. 2009. Analisis Kepuasan Konsumen dalam Memilih Coffee Shop di Kota Malang. Medan: Repositori Institusi USU

Wang, C. Y., \& Lin, C. H. 2010. A Study of The Effect of TV Drama on Relationships among Tourist' Experiential Marketing, Experiential Value and Satisfaction. International Journal of Organizational Innovation, 3, 107 $-123$.

Wijayanti, I. D. 2008. Manajemen. (A. Setiawan, Ed.) Yogyakarta: Mitra Cendikia. 
